\title{
AUTOMATED UNDERWAY OCEANIC AND ATMOSPHERIC MEASUREMENTS FROM SHIPS
}

Shawn R. Smith ${ }^{(1)}$, Mark A. Bourassa ${ }^{(1)}$, E. Frank Bradley ${ }^{(2)}$, Catherine Cosca $^{(3)}$, Christopher W. Fairall ${ }^{(4)}$, Gustavo J. Goni ${ }^{(5)}$, John T. Gunn ${ }^{(6)}$, Maria Hoo ${ }^{(7)}$, Darren L. Jackson ${ }^{(8)}$, Elizabeth C. Kent ${ }^{(9)}$, Gary Lagerloef ${ }^{(6)}$, Philip McGillivary ${ }^{(10)}$, Loic Petit de la Villéon ${ }^{(11)}$, Rachel T. Pinker ${ }^{(12)}$, Eric Schulz $^{(13)}$, Janet Sprintall ${ }^{(14)}$, Detlef Stammer $^{(15)}$, Alain Weill ${ }^{(16)}$, Gary A. Wick ${ }^{(17)}$, Margaret J. Yelland $^{(9)}$

${ }^{(1)}$ Center for Ocean-Atmospheric Prediction Studies, Florida State University, 236 R. M. Johnson Bldg., 32306-2840 Tallahassee USA, Email: smith@coaps.fsu.edu, mbourassa@coaps.fsu.edu

${ }^{(2)}$ CSIRO (Commonwealth Scientific and Industrial Research Organisation) Land and Water, PO Box 1666, Canberra, ACT 2601, Australia, Email: Frank.Bradley@ csiro.au

${ }^{(3)}$ NOAA/PMEL (National Oceanic and Atmospheric Administration/Pacific Marine Environment Laboratory), 7600 Sand Point Way NE, Seattle, WA 98115, USA, Email: cathy.cosca@noaa.gov

(4) NOAA/ESRL/PSD (National Oceanic and Atmospheric Administration/ Earth System Research Laboratory/Physical

Science Division), R/PSD3, 325 Broadway, Boulder, CO 80305-3328, USA, Email: Chris.Fairall@ noaa.gov

${ }^{(5)}$ USDC/NOAA/AOML/PHOD (University of California, San Diego/National Oceanic and Atmospheric

Administration/Atlantic Oceanographic and Meteorological Laboratory/Physical Oceanography Division), 4301 Rickenbacker Causeway, Miami, FL 33149, USA, Email: Gustavo.goni@ noaa.gov

${ }^{(6)}$ Earth and Space Research, 2101 Fourth Ave., Suite 1310, Seattle, WA, 98121, USA, Email: gunn@esr.org, lager@esr.org

${ }^{(7)}$ Intergovernmental Oceanographic Commission UNESCO (United Nations Educational, Scientific and Cultural Organization), 1, rue Miollis, 75732 Paris Cedex 15, FRANCE, Email: m.hood@unesco.org

${ }^{(8)}$ Cooperative Institute for Research in Environmental Sciences, NOAA/ESRL/PSD, 325 Broadway, R/PSD2, Boulder, CO 80305, USA, Email: Darren.L.Jackson@ noaa.gov

${ }^{(9)}$ National Oceanography Centre, European Way, Southampton, SO14 3ZH, UK, Email: eck@ noc.soton.ac.uk, miy@noc.soton.ac.uk

${ }^{(10)}$ United States Coast Guard, PO Box 5082, Alameda, CA, 94501-8582, USA, Email: Philip.A.McGillivary@uscg.mil

${ }^{(11)}$ IFREMER (French Institute for Exploitation of the Sea/Institut Français de Recherche pour l'Exploitation de la Mer), BP 70, 29280 Plouzané, France, Email: loic.petit.de.la.villeon@ifremer.fr

${ }^{(12)}$ Department of Atmospheric and Ocean Science, Space Sciences Building, University of Maryland, College Park, MD, 20742, USA, Email: pinker@ atmos.umd.edu

${ }^{(13)}$ Centre for Australian Weather and Climate Research, Bureau of Meteorology, GPO Box 1289, Melbourne, Vic 3001 Australia, Email: e.schulz@ bom.gov.au

${ }^{(14)}$ Scripps Institution of Oceanography, 9500 Gilman Drive, La Jolla, CA, 92093-0230, USA, Email: jsprintall@ucsd.edu

${ }^{(15)}$ University of Hamburg, Institut für Meereskunde, Bundesstr. 53, 20146 Hamburg, Germany, Email: detlef.stammer@zmaw.de

${ }^{(16)}$ LATMOS (Laboratoire Atmosphères, Milieux, Observations Spatiales), 10-12 Avenue de l'Europe, 78140 Vélizy, France, Email: alain.weill@ cetp.ipsl.fr

${ }^{(17)}$ NOAA/ESRL/PSD (National Oceanic and Atmospheric Administration/ Earth System Research Lab/ Physical Science Division), R/PSD2, 325 Broadway, Boulder, CO 80305, USA, Email: Gary.A.Wick@ noaa.gov

\begin{abstract}
Merchant, cruise, and research vessels make unique contributions to marine data collection using automated oceanic and atmospheric monitoring systems. The programs making these observations are reviewed along with the wide range of applications to atmospheric and oceanic research and operations. A vision for the next decade outlines where incremental improvements to instruments, platforms, and data stewardship can benefit the community. A series of recommendations are made to meet the challenges of future-ocean observing.
\end{abstract}

\section{INTRODUCTION}

Shipboard atmospheric measurements include winds, humidity, air temperature, pressure, precipitation, and downwelling global solar (shortwave) and longwave radiation. Occasionally vessels deploy net, ultraviolet, and photosynthetically active radiometers. Ocean measurements include sea surface temperature, salinity, and sometimes florescence and dissolved oxygen. Measurements may include atmospheric and oceanic $\mathrm{pCO}_{2}$ [39], direct fluxes [16], radiative SST (Sea Surface Temperature) [13], currents, sea state [58], and bathymetry. These data are compiled, 
distributed, and archived by national weather and ocean services, research institutions, armed forces, and philanthropic corporations. The range of variables measured, data density, and data quality is unique to these seagoing observing systems.

This review focuses on automated underway systems that continuously collect observations at intervals of one-minute or less. For meteorology and sea surface temperature, the sampling rates exceed those made by vessels participating in the Voluntary Observing Ship Scheme [29]. While ships can make measurements using towed instrumentation [50], cabled profiling systems [23], and atmospheric balloons, this paper focuses on systems that collect data from instruments directly mounted on the vessel.

Ships can make concurrent measurements while on another mission (e.g. commerce, science, deploying buoys and floats), making vessels an integral part of the observing system. Automated systems provide underway observations from shipping lanes and coastal regions (mostly commercial vessels) and the sparsely observed Southern Ocean (research and resupply vessels). Such data are not routinely assimilated into numerical weather prediction (NWP) models, however, due to their high-temporal sampling and independence from NWP, they are used for a wide range of applications (Sect. 4).

\section{VESSELS MAKING AUTOMATED UNDERWAY OBSERVATIONS}

The two primary platforms for automated underway observations - research (e.g. Fig. 1a) and merchant vessels - provide complementary spatial sampling of the ocean. Merchant vessels operate in well-defined shipping lanes providing long-term, year-round observations along transect lines. Repeat sampling along transects allows separation of the space and time variations in the observations. By contrast, research vessels (RVs) tend to operate outside shipping lanes, providing snapshots of conditions in remote regions (e.g. south Pacific, Southern Ocean). In some cases, RVs occupy the same line on an interannual to decadal basis as part of the global repeat hydrography program [23]. A new SCOR/IAPSO (Scientific Committee on Oceanic Research /International Association for the Physical Sciences of the Oceans) 'OceanScope' Working Group aims to establish a global network of commercial ships making sustained observations of the ocean water column [51].

Deploying underway sensors on merchant vessels poses challenges. Limited options for locating instrumentation and accessing seawater complicate deployments. Many merchant operators are receptive to science operations, but require fully autonomous observing systems as they often lack berthing for dedicated ocean-observing technicians (ship riders). Requirements for scientific sampling in the design of future merchant vessels are being investigated through JCOMM (Joint WMO-IOC (World Meteorological Organization-International Oceanographic Commission) Technical Commission for Oceanography and Marine Meteorology) ${ }^{1}$.

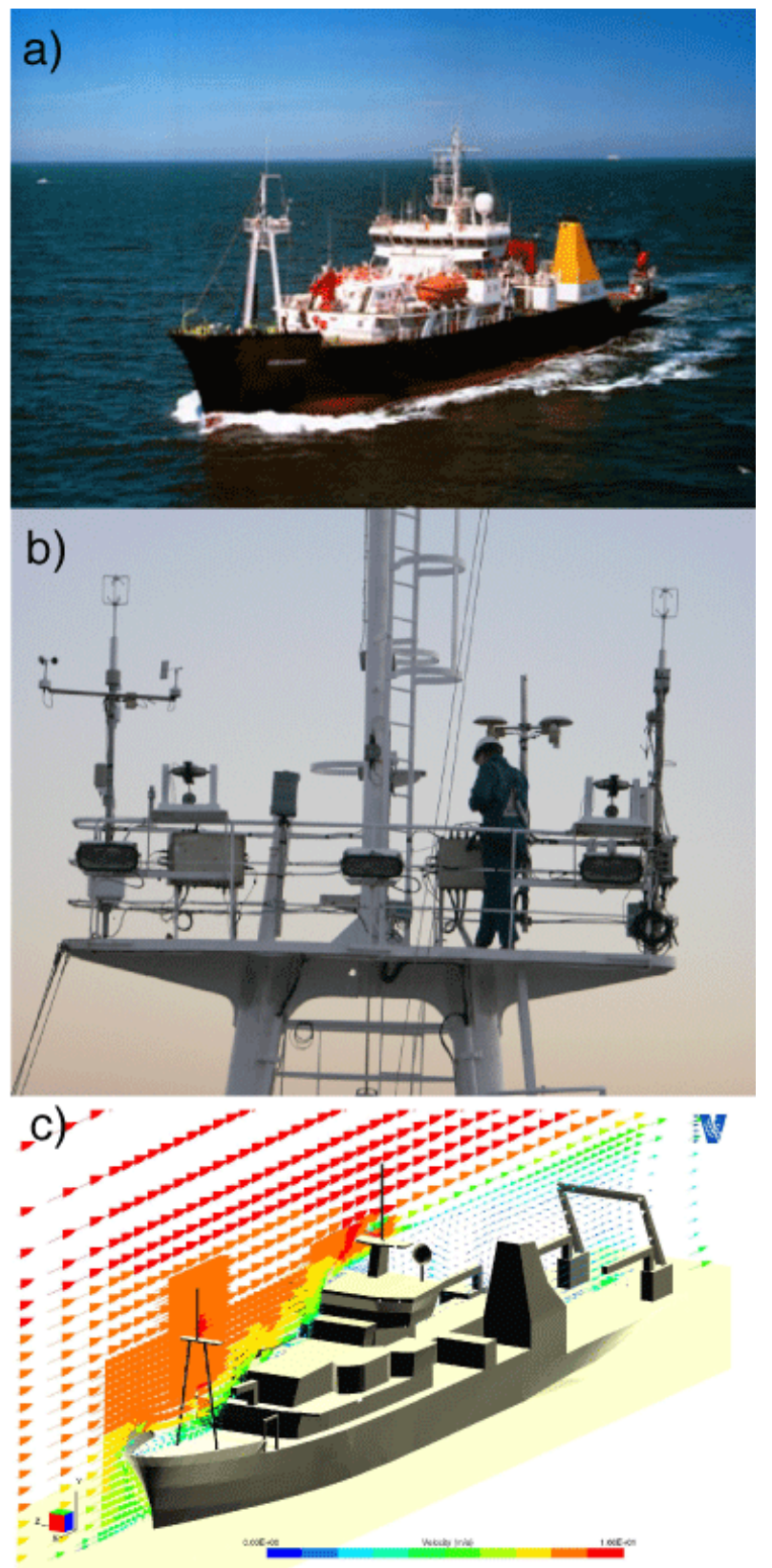

Figure 1. Research Vessel RRS (Royal Research Ship)

Discovery a) making underway measurements, $b$ ) instrumented for air-sea fluxes and c) modeled for airflow distortion.

\footnotetext{
1 Joint World Meteorological Organization (WMO)/Intergovernmental Oceanographic Commission (IOC) Technical Commission for Oceanography and Marine Meteorology
} 
By contrast, RVs exist to facilitate ocean observations, can support a wide range of sensors (Fig. 1b), and generally have technicians aboard for routine sensor maintenance. Data quality is significantly improved when shore-side personnel monitor the automatedunderway observations and communicate problems directly to a shipboard technician [57].

Automation of underway observations is cost-effective for obtaining continuous high-quality data at the air-sea interface, which benefits a range of climate applications (e.g. air-sea fluxes, water mass properties, oceanic heat content, and oceanic uptake of carbon). Automated systems can sample at spatial and temporal resolution needed to examine small-scale variability of properties (e.g. temperature, salinity, $\mathrm{CO}_{2}$ ) and derived air-sea fluxes. They sample the ocean and atmosphere even during periods when conditions are unsafe for deck operations, or when crew workloads do not allow time for manual observations. Some limitations do exist. When not well monitored, automated systems can result in large quantities of undocumented and poorly calibrated data. The lack of automated sensors to measure certain parameters (e.g. cloud type and cover, waves, sea state) requires manual observations.

\section{UNDERWAY OBSERVING IN PAST DECADE}

Research and operational users appreciate the ability of automated underway systems to acquire high quality, frequently sampled, oceanic and atmospheric measurements. The following examples of underway ship-based observing programs (Sect. 3.1) illustrate the diversity of measurements collected in support of user requirements (Sect. 4). Additional specialized automated sensors are deployed on ships (Sect. 3.2), but currently are not managed via a specific data stewardship program.

\subsection{Programs}

The Shipboard Automated Meteorological and Oceanographic System (SAMOS) initiative (http://samos.coaps.fsu.edu) began collecting, quality controlling, and distributing observations from RVs in 2003. The SAMOS initiative is detailed in [57].

The Integrated Marine Observing System (IMOS; http://www.imos.org.au) observes the oceans around Australia [1]. Since 2008, IMOS has obtained routine meteorological and surface ocean observations from two RVs: the Southern Surveyor, which performs research cruises in seas adjacent to Australia; and the Aurora Australis, which conducts Southern Ocean research and Antarctic resupply missions. Both vessels are equipped with routinely calibrated instruments necessary to obtain bulk flux estimates. Data are telemetered to Australia, quality controlled, and made available to researchers.

The SAMOS initiative and IMOS are complementary to the JCOMM Voluntary Observing Ship (VOS) Scheme [29] with some vessels contributing to all three programs. Traditional VOS observations are at much lower temporal resolution than SAMOS/IMOS, typically between hourly and six-hourly, to meet objectives such as the initialization of NWP models and providing input to marine climate data sets. When RVs report to VOS, they typically use a mixture of meteorological instruments provided by National Meteorological Services (NMS) and visual observations. Therefore, RVs may carry two sets of meteorological instruments: one of research quality provided by the operator and the other for routine weather observations provided by the NMS. The VOS Scheme has not systematically recruited RVs using their own instruments because of concerns about consistency and continuity. More VOSs are being fitted with automated weather systems (AWS), some basic systems, but some of similar quality to those utilized by SAMOS and IMOS.

The Global Ocean Surface Underway Data (GOSUD; http://www.ifremer.fr/gosud/) project was established by the International Oceanographic Data Exchange (IODE) to collect, process, archive and disseminate in real-time and delayed mode, sea surface salinity and other underway variables collected by research and commercial ships. An overview is provided in [45].

Although the JCOMM Ship Of Opportunity Program (SOOP) focuses on eXpendable BathyThermographs (XBT) [19], SOOP also provides platforms for automated underway measurements from Acoustic Doppler Current Profilers (ADCP), $\mathrm{CO}_{2}$ systems, and thermosalinographs (TSGs). The latter complement SSS (Sea Surface Salinity) observations from profiling floats [48] by providing data at different temporal and spatial scales. Complementing and contributing to GOSUD, NOAA's (National Oceanic and Atmospheric Administration) Atlantic Oceanographic and Marine Laboratory provides TSG data to the GTS Global Telecommunication System) for $\sim 80$ vessels (Fig. 2).

The scientific community has directed considerable effort and resources toward assessing air-sea carbon flux. Automated units are placed on cargo, cruise and research ships to create seasonal air-sea $\mathrm{CO}_{2}$ flux maps for all regions of the ocean. The International Ocean Carbon Coordination Project (IOCCP), sponsored by UNESCO-IOC (United Nations Educational, Scientific and Cultural Organization/Intergovernmental Oceanographic Commission) and SCOR, "promotes the development of a global network of ocean carbon measurements" (http://www.ioccp.org). Additional details can be found in [39]. 


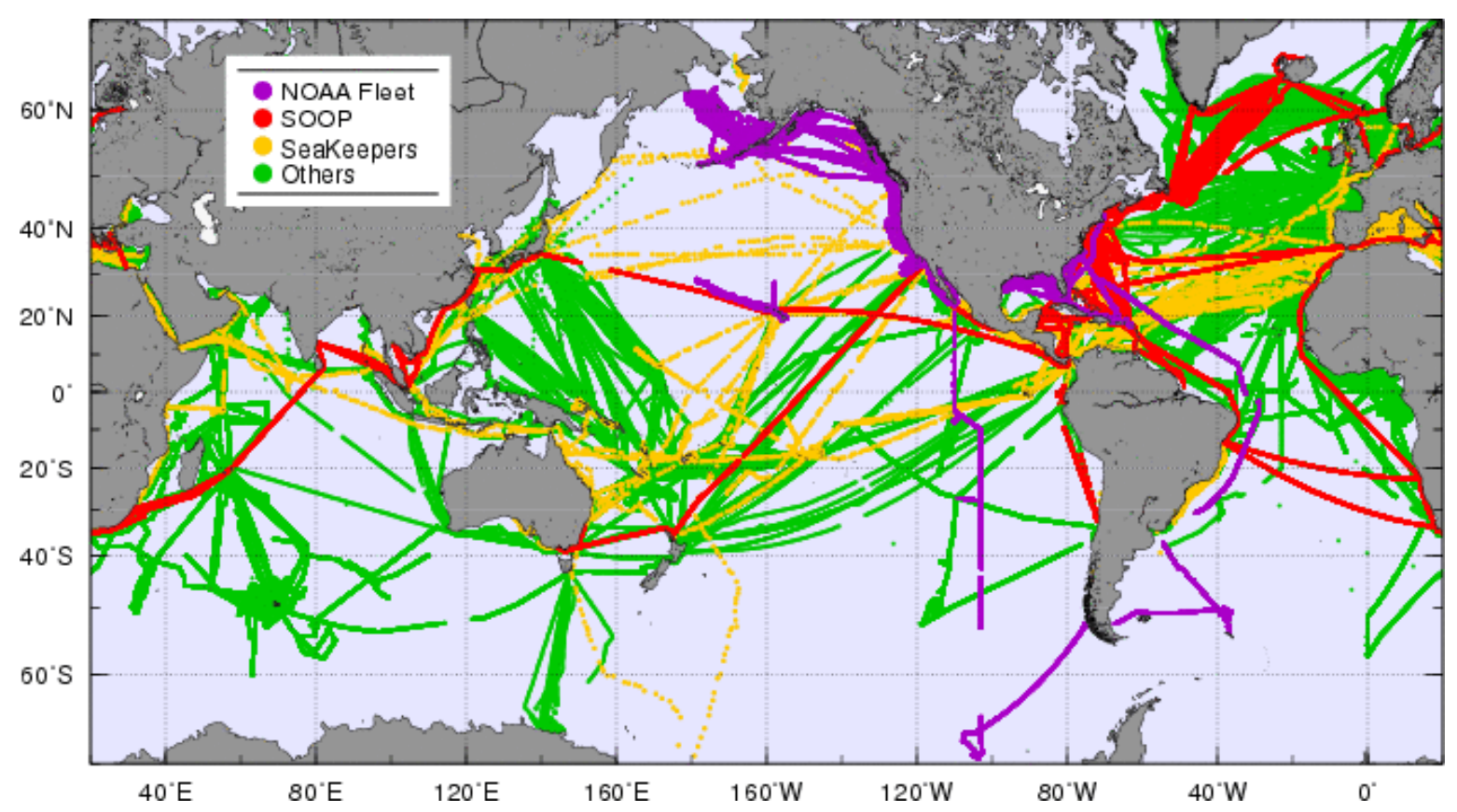

Figure 2. TSG observations transmitted into the GTS and to the Coriolis data center (http://www.coriolis.eu.org/) during the period 2003-2009.

The private sector also contributes through, for example, the International SeaKeepers Society (http://www.seakeepers.com/). SeaKeepers has collected automated underway observations from private yachts, cruise ships, and some merchant vessels since 2000.

\subsection{Sensors}

ADCPs have been widely deployed to measure upper ocean currents on both merchant and research vessels. Although the Joint Archive for Shipboard ADCP (http://ilikai.soest.hawaii.edu/sadcp/) acquires calibrated and validated ADCP data, which they distribute to the user community, the archive primarily handles U. S. cruises and observations from a few multi-national programs. Individual projects have also shown the utility of ADCP measurements for regional science (e.g. [17]). However, over 95\% of shipboard ADCP data are not included in the Joint Archive due to the lack of quality control of the navigation and ADCP data (P. Caldwell, personal communication, 2009).

Different types of ship borne radars have been deployed, primarily on RVs, to measure wind, precipitation, sea state, and wave properties [15 and 43]. New phase array systems for ship borne atmospheric wind profiling have recently been developed [32]. Both X-band radar (e.g. [69 and 40]), which estimates wave properties and currents, and Xband Doppler radar, which is sensitive to precipitation and sea state, can be routinely used on ships.

The ship-borne wave recorder (SBWR) uses vessel motion and pressure sensors to derive surface elevation
[61] and hence 1-D wave spectra and wave height [22]. A complete description of sea state requires both SBWR and radar systems to provide directional information, but RVs carry at most one system. The exception is the Ocean Weather Ship Polarfront, which has a SBWR since 1978 and a wave radar system since 2006. Comparison of data from Polarfront showed that wave heights from the wave radar were often significantly overestimated, particularly in low/moderate wind speeds where the sea state was swell-dominated [72].

Sensor requirements for measurement of direct fluxes and flux related variables are described in [16 and 63]. Presently, RVs provide almost all direct flux measurements and the large number of accompanying measurements needed to characterise atmospheric conditions and develop flux parameterisations. To allow routine direct flux measurements on ships and their expansion to dedicated flux moorings will require improved gas and aerosol flux sensors, including accurate and low-power sensors for precipitation, $\mathrm{CO}_{2}$ (carbon dioxide), ozone, $\mathrm{SO}_{2}$ (Sulfur dioxide) and DMS (Dimethylsulfide).

\section{APPLICATIONS OF UNDERWAY SHIP DATA}

Automated underway data support many applications and more applications would open up if data were more accessible [20]. The characteristics of underway data - high quality, high temporal resolution, and high spatial resolution along ship tracks - are ideal for applications including air-sea interaction studies, 
model validation and satellite calibration and validation. Their sparseness, relative to VOS or drifting buoys, prevents direct construction of gridded datasets, although underway data enhance gridded datasets particularly in data-sparse regions. Underway data are particularly valuable for applications requiring close matching in space and time to validation datasets, for applications where high data quality is important, and where a wide range of measured variables is required.

Underway data are presently used to study air-sea interactions [16]. RVs provide the measurements of turbulent and radiative fluxes used to develop flux parameterisations (e.g. [14]) but also provide important data for evaluating gridded flux products and estimates of basic meteorological parameters, such as winds, air temperature, humidity, and cloud cover used in the parameterisation of surface fluxes (e.g. [56]).

Expanded underway atmospheric and surface oceanic measurements from ships offer an opportunity to understand variability at different spatial and temporal scales and to assess uncertainty in air-sea heat and freshwater fluxes. For example, in the poorly sampled Southern Ocean air-sea fluxes change surface water density to form Intermediate and Mode Waters that contain fingerprints of their contact with the atmosphere. High sea state and wind conditions deter deployment of surface buoys in the Southern Ocean and merchant ship traffic is infrequent. Although several countries routinely operate their RVs in the Southern Ocean (e.g. Nathaniel Palmer, Polarstern, Aurora Australis), these transects typically occur only in the austral summer. The Lawrence M. Gould does provide year-round underway measurements in Drake Passage. Given the paucity of surface meteorological measurements available, this comprehensive suite of shipboard data enables one of the few data-based bulk turbulent flux evaluations of the air-sea heat fluxes estimated by satellites or reanalysis products. Existing NWP, satellite, and in situ air-sea flux products differ substantially in the Southern Ocean (Fig. 3), with the largest imbalances occurring during the winter when few in situ measurements are available [11]. Improving our estimates of air-sea fluxes by evaluation against shipboard meteorological data should improve the physical understanding of climate-scale processes that occur in the Southern Ocean.

Underway data have been extensively used in the development of satellite retrieval algorithms and for validating satellite measurements. Examples include the development of algorithms for humidity and air temperature [55] and [25] and validation for satellite wind measurements (Fig. 4; [4] and [5]). High quality data are needed under all conditions and ships provide measurements in regions unsampled by other observing system components. The high spatial and temporal variability of underway samples allow closer matching
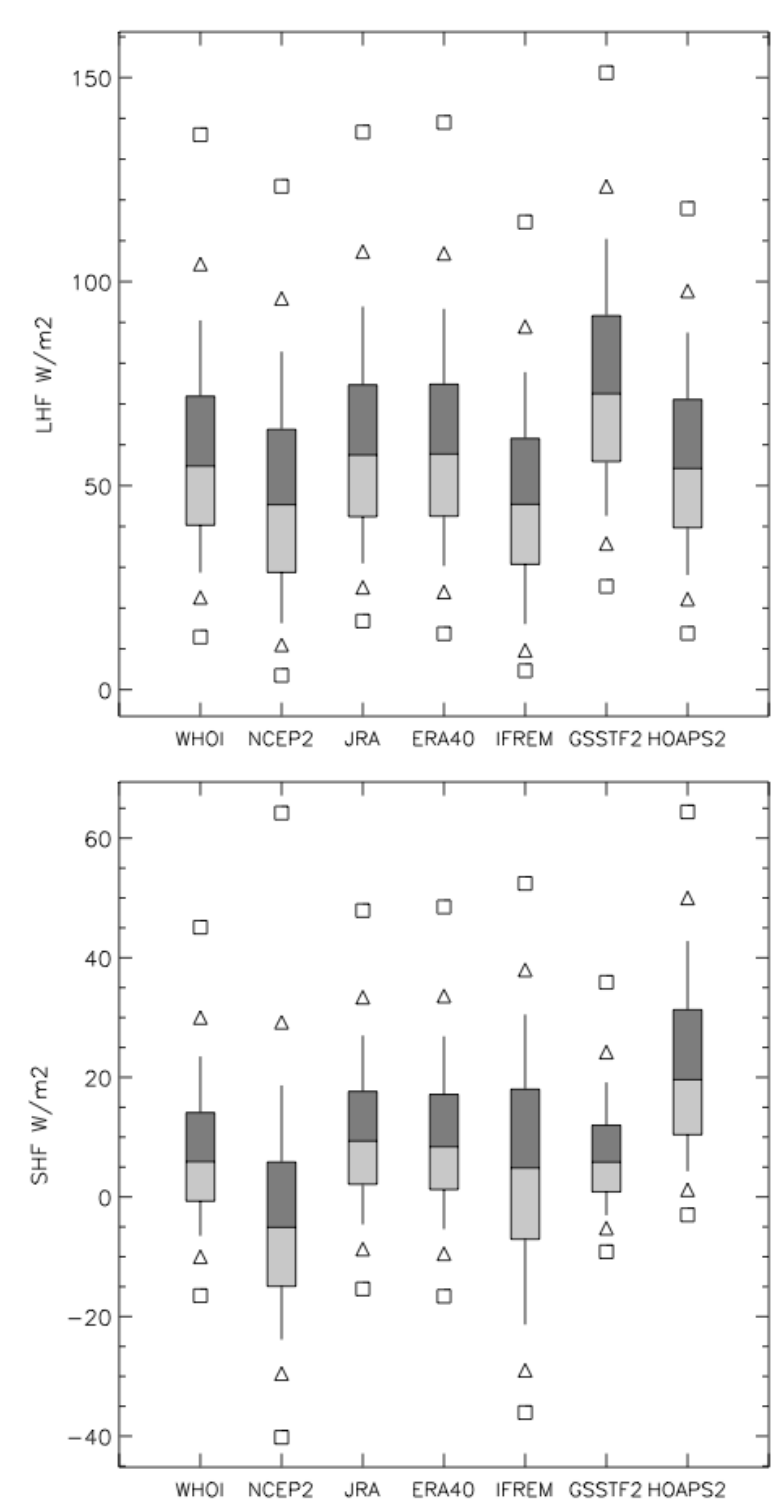

Figure 3. Box plots showing differences in (top) latent and (bottom) sensible heat flux estimates from seven monthly air-sea flux products in the Southern Ocean $\left(40^{\circ} \mathrm{S}-60^{\circ} \mathrm{S}\right.$, $0^{\circ} \mathrm{E}-359^{\circ} \mathrm{E}$ ). The comparison is for March 1992 through

December 2000. The box bounds the 75th and 25th quartiles and the bar through the box is the median. The whiskers extend to the 90th and 10th percentiles. Triangles (squares) mark the 95th and 5th (99th and 1st) percentiles.

to the satellite footprint, than buoy data. This is particularly important for wind speed and direction. Satellite retrievals of surface humidity have been validated using underway data (e.g. [54]) exposing significant differences and regional bias among satellite retrievals [25] and [26].

The global distribution of precipitation is critical for our understanding and modeling of climate processes, including the freshwater and energy cycles [60] and [59]. Rain gauges are common over land, but over the oceans in situ sampling is sparse. Radar coverage is 
limited to coastal sites and occasional shipboard systems (e.g. Ronald Brown). Of the meteorological variables measured on ships, precipitation seems to be the most problematic. This is partly due to known difficulties with sensors [63], which are susceptible to large errors associated with flow distortion over the ship and partly to the short spatial and temporal scales of rainfall. Large unresolved differences among precipitation from satellites and models [2] points to the need for renewed effort to improve existing shipboard rain gauges and develop new ones.
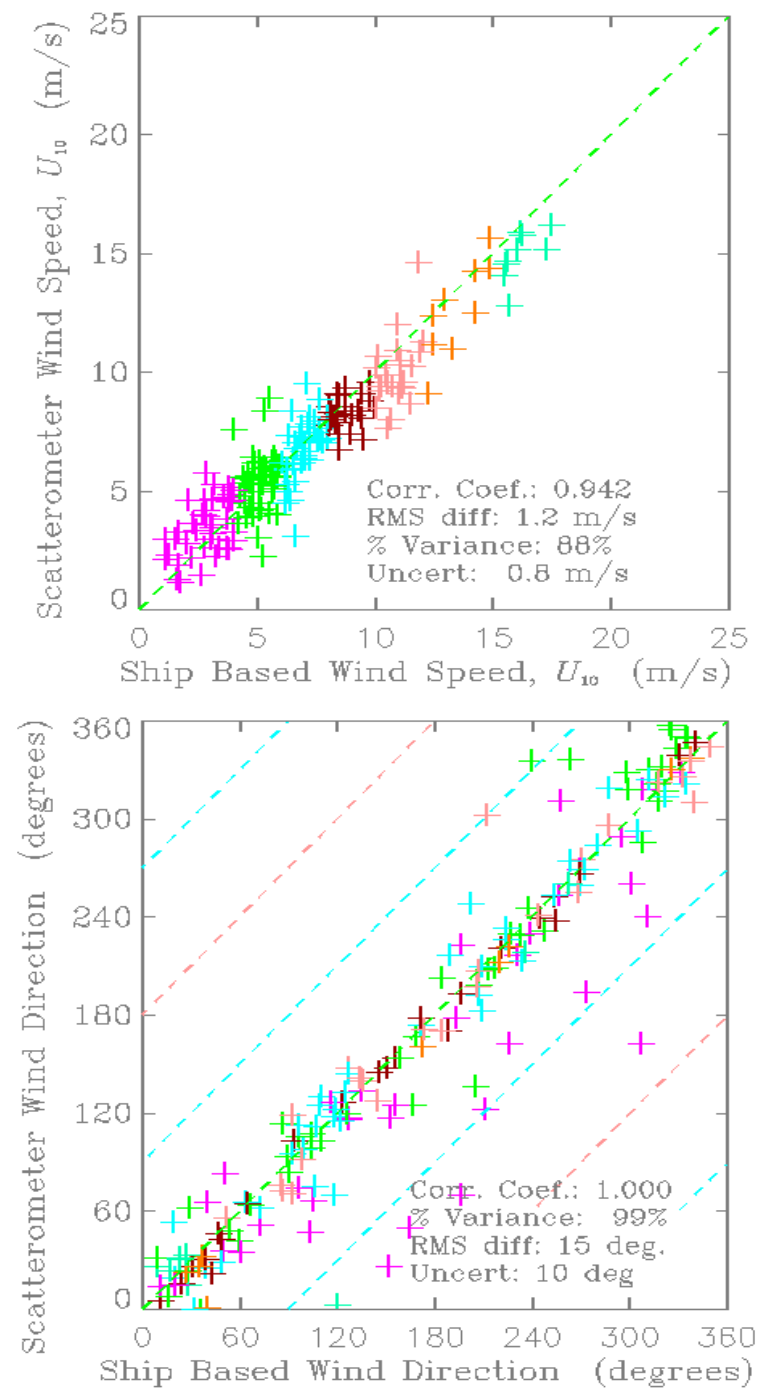

Figure 4. Difference between co-located 10-m wind (top) speed and (bottom) direction from research vessels and the Seawinds scatterometer on QuikScat. Crosses are color coded by the ship wind speed.

Many automated underway observations (exceptions: VOS and SOOP) are not assimilated into operational atmospheric or oceanic models. This makes these observations valuable for verifying operational atmospheric and oceanic products. Underway observations have been used to validate NWP model output [56] and [48]. Starting in mid-2008, the Australian IMOS observations are used to verify operational marine forecasts. The U.S. National Weather Service has similar interests for forecast validation with regards to SAMOS observations.

Underway TSG have excellent spatial resolution (approximately $3 \mathrm{~km}$ for quality-controlled data) along the track of the ship, allowing precise location of surface oceanic fronts. TSG sampling complements that from profiling float data, which have sparse spatial and temporal coverage in regions of strong ocean divergence while regions of high eddy activity are over represented. TSG-derived SSS have been used to identify the edge of the surface fronts and the barrier layer of the western tropical Pacific (WTP) warm pool, where ocean-atmosphere interactions are of critical importance to interannual variations associated with El Niño-Southern Oscillation (ENSO; [34]). In the Southern Ocean, SST from the TSG on the Lawrence $M$. Gould is used to detect the location of the relatively narrow ( 30-70 km) Polar Front in the Drake Passage [10]. A frontal shift can modify key regions of air-sea heat exchange associated with Mode Water formation, which plays an important ventilation role in the meridional overturning circulation. Rapid air-sea flux variations on small spatial scales associated with mesoscale ocean features (i.e. fronts or eddies) may provide a coupling feedback between wind and SST variability that possibly sustains the frontal variability. Existing NWP air-sea flux fields fail to capture these small-scale features.

Underway observations are also used to understand the influence of the ship itself on observations. The presence of the ship influences wind speed (Fig. 1c; [71], [47], [35], [36] and [37]), surface fluxes [70] and [42], and air temperatures [3]. Research has led to recommendations for sensor placement on vessels [7] and to bias corrections the ship.

\section{VISION FOR COMING DECADE}

An expanding role for automated underway observations is envisioned from both research and merchant ships as part of the Global Ocean Observing System (GOOS). New measurements using existing technology will address new challenges in oceanography, marine biology, satellite studies, and air-sea interaction. Comparisons between different technology on single vessels and between vessels and other components of the observing system are needed to improve our understanding of the characteristics of different types of underway measurements. Advances in instrumentation and technology are also needed to obtain global sampling. Finally, the expansion of routine stewardship of underway data from the wide array of shipboard observing systems is necessary. The 
versatility of vessels to deploy multiple sensors in a wide range of ocean environments makes them a valuable resource to support a wide range of activities relevant to society.

\subsection{New measurements and applications}

Using existing technology, many applications can be addressed by expanding underway measurements; the following list is by no means comprehensive. Separate community white papers address the needs for fluxes of heat, momentum, and freshwater [16] and carbon [39].

- Expanding access to TSG measurements from ships will address topics ranging from small-scale ocean features (e.g. fronts, river outflow and eddies) to tropical variability. For example, the lack of equatorial SSS observations limits understanding of the role of SSS anomalies in preconditioning of ENSO and of decadal modulations of equatorial heat content. Improving access to TSG data from vessels operating in the tropics could be of critical importance for future prediction of ENSO events.

Earth observing satellites will remain a primary component of GOOS.

- High-quality surface data are needed to calibrate/validate satellite sensors. One example is for upcoming satellite salinity missions [31]. Prelaunch error analysis for Aquarius revealed a need for additional in situ sampling of SSS in the lowsalinity Alaskan Gyre and in regions of high salinity and strong gradients. Underway measurements reveal horizontal variability and, when combined with vertical profiles, can provide information on correlation scales. Satellite salinity data will help understanding of the water cycle and its role in climate. Shipboard wind measurements will continue to provide important validation for new satellite wind sensors [6] with RVs providing constraints for satellite retrievals under high wind and sea-state conditions.

- In situ measurements of marine precipitation are needed for validation of satellite-borne precipitation sensors (e.g. Tropical Rainfall Measurement Mission [TRMM] and the Global Precipitation Measurement [GPM] satellites due for launch beginning 2013). Present validation relies on coastal and island-based radar sites. Algorithm retrieval errors are strongly dependent on meteorological regime [44] and open ocean validation data are urgently required. Ships equipped with credible precipitation instruments, possibly including stabilized rain radars, would fill an important role in the validation of space-based precipitation. Development of improved sensors and extensive sensor comparisons are needed for these applications.

- Increased sampling density and improved accuracy of precipitation measurements from ships would benefit coupled models. Regional knowledge of net freshwater input to the ocean is crucial for determining the effect of changing precipitation patterns on ocean circulation. Closure of the upper ocean heat and freshwater budgets from shipboard surveys is possible (e.g. [65]) and offers another possibility for space-borne sensor validation.

- Expanding deployments of radiation sensors on ships will support an active community (e.g. Baseline Surface Radiation Network, [41]; Surface Radiation Budget project; http://www.gewex.org/srb.html) working to improve satellite-based inference schemes to estimate climatically and biologically important components of surface radiative fluxes. These include the total shortwave $(0.3-4.0 \mu \mathrm{m})$; Near-IR (Infrared) (0.7-4.0 $\mu \mathrm{m})$; photosynthetically active radiation (PAR (Photosynthetically Available Radiation); 0.40-0.70 $\mu \mathrm{m}$ ) and UV-B (type B ultraviolet) $(0.28-0.32 \mu \mathrm{m})$. Few direct radiation measurements exist over the ocean to evaluate satellite estimates. Demand for PAR is increasing from ocean biologists and is needed to understand the carbon cycle and primary productivity in the oceans. PAR is commonly estimated from total shortwave using a single conversion factor; however, this factor is not globally applicable (R. Pinker, personal communication, 2008). Validation of satellite-derived PAR estimates requires more in situ observations. Collecting a full suite of surface radiation measurements from ships will support research on oceanic primary production and impacts of ultraviolet radiation on marine organisms with direct relevance to human activities (food supply, carbon sequestration, etc.).

\subsection{Comparison of instruments and systems}

Alongside expanded use of existing technology, we must improve our understanding of observation characteristics through dedicated sensor and system comparisons.

Challenges to making meteorological observations on ships include the varying quality of instrumentation deployed and locating sensors to limit heating and airflow distortion by the ship. NOAA therefore made selective deployments of a portable direct air-sea flux instrument suite used to benchmark vessel-operated instrumentation providing observations to the SAMOS data center. Deployments in 2008 revealed problems with wind sensor locations [66]. Systematic shipboard comparisons between multiple sensor systems (e.g. NMS sensors for VOS, vessel operated SAMOS, and 
portable reference standards) are needed to enhance the utility of underway data. For example, applying these data to satellite calibration and validation studies requires absolute calibration across the range of underway systems and vessel types.

Comparison of SSS obtained from different models of TSGs, and between TSGs and other platforms (i.e. profiling floats and CTDs (Conductivity, Temperature, and Depth)) is needed. Each TSG installation should include external temperature measurement, as temperatures inside the TSG are often warm biased due to the TSG location inside the vessel. TSG quality control would be improved by the development of automated water sample collection systems. The partial pressure of $\mathrm{CO}_{2}$ in surface seawater $\left(\mathrm{pCO}_{2 \mathrm{sw}}\right)$ requires concurrent TSG measurements: sea temperature for adjustment to represent conditions in the surface water and SSS to delineate surface waters and for interpretation of the $\mathrm{pCO}_{2 \mathrm{sw}}$ data. Therefore, all installations of $\mathrm{pCO}_{2}$ systems must be accompanied by TSG installations along with provisions for TSG data quality control.

The underway community should coordinate with existing programs to provide for inter-platform comparisons. For example, the Alliance for Coastal Technologies (ACT, http://www.act-us.info/) has completed several inter-calibration field experiments for marine sensors. Although ACT focuses on the coastal environment, coordination with ACT would take advantage of lessons they have learned.

RVs play a key role in the sensor comparisons needed to meet GCOS Climate Monitoring Principles [18]. They provide the capability for long-term comparison of new and existing technologies to determine the characteristics of both old and new measurements, for example the comparison of wave measurements from SBWR and wave radars. It is also possible to provide visual observations of clouds and sea state to allow improved parameterisations and bias adjustments to be developed ensuring better use of the multi-decadal record of such observations.

\subsection{Instrument and platform development}

Present automated technology does not meet all the needs anticipated for future marine observations. Additional technology development is therefore needed in the coming decade.

Clouds have important effects on radiation and precipitation, which depend on cloud height, thickness, horizontal extent, horizontal variability, water content, phase (liquid or ice), and sizes of droplets and crystals. The visual appearance of clouds is often taken to indicate characteristic atmospheric dynamical processes, so the traditional classification by weather observers on VOS of cloud types based on their appearance [68] continues to be a useful classification in studies of cloud processes [24]. Development of an automated cloud identification system would be a significant advancement for observations over the ocean. Although all sky cameras are in existence (e.g. Total Sky Imager, http://www.arm.gov/instruments/instrument.php?id=tsi ), only recently have they been deployed on ships for automated cloud measurements over the ocean.

Requirements for, and benefits of, an enhanced global wave observation network, including in situ observation systems and complementary remote sensing systems, are outlined in [58]. In-situ directional wave measurements support a range of forecasting, climate, and research applications and for calibration/validation of satellite wave sensors. There is a need for development of SBWR [22], no longer manufactured commercially, and the wave heights from the wave radar systems require improvement [72] for wider deployment on RVs and merchant vessels.

In addition to wave radar, development/improvement of other remote sensing instruments for ship deployment is recommended. Upward looking wind and temperature profilers (widely used at land-based stations) can be further adapted for operation and deployment on ships to measure lower atmospheric temperature, humidity, and wind structure. Automated profilers could aid satellite retrieval algorithm development in regions of strong vertical temperature inversions. Automated, low power, vertically pointing $\mathrm{X}$-band Doppler radar would be needed to derive precipitation rates very close to the surface $(\sim 100 \mathrm{~m}$ height). Improving precipitation rates can be accomplished using dual polarimetric S- and X-band radar (e.g. [52]). Further improvements to in situ precipitation measurements on ships can be accomplished by first calibrating a radar using shore based rain gauges [28] or disdrometers [33] and then deploying the calibrated radar at sea to validate ship rain gauges.

Technology advancements are needed improve estimates of air-sea fluxes and the surface radiation budget. New sensors are necessary for routine measurement of the near-surface ocean current vector, to correct the true wind in flux algorithms, especially in the tropics. Wider measurement of accurate radiometric SST [12] requires additional sensor development to reduce costs. Mechanisms to measure direct solar radiation, to shield the bodies of pyrgeometers to prevent solar heating, and to clean radiometer domes (removing dust, soot, and guano) need to be developed.

Additional improvements can be made in the next decade to the vessels used to make underway observations. The shape of a ship has a large influence on the magnitude of the flow distortion experienced by 
an anemometer on a bow mast. A bluff superstructure (common to ice breakers) causes more flow distortion than a streamlined one, and a tall mast well away from the superstructure is preferable to a short one close to the superstructure. These considerations were taken into account during the design phase of the UK's newest RV the RRS James Cook [38] and airflow modeling is has been conducted to optimize meteorological sensor placement on the new Alaskan Regional Research Vessel. These results should be applied to future merchant and RV design.

New autonomous surface vessels (ASVs) could expand the coverage of marine underway observations. Technology under development ranges from small kayaks [9] and WaveGliders (http://www.liquidr.com/) to large robotic vessels [46] and [67]. These new technologies are becoming viable to provide ocean surface and atmospheric measurements (Fig. 5). Robo-
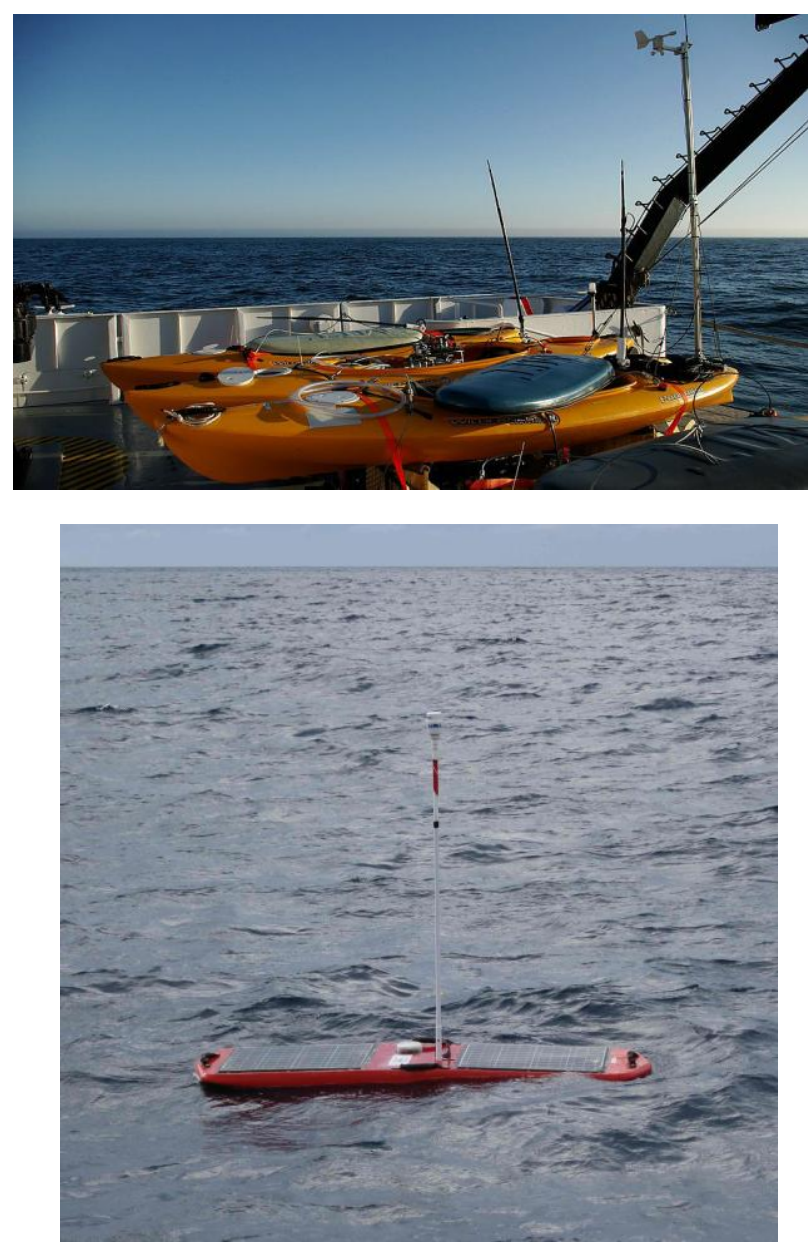

Figure 5. Autonomous surface vessels: (top) robo-kayak with anemometer and mini-winch CTD and (bottom) WaveGlider with sensor mast (wind, humidity, pressure, and temperature).

kayaks are one of the more cost effective ASVs, and can measure winds, air and sea temperature and carry a winch for conducting measurements of conductivity, temperature, and depth (CTD) to a depth of $150 \mathrm{~m}$. WaveGliders, another relatively inexpensive ASV, are more stable than robo-kayaks in rough seas. Several ASVs use solar panels to provide power for sensor payloads and future technology to harvest wave energy may extend the duration of missions. ASVs with new communication technologies (e.g. disruption tolerant wireless networking) will allow data collection from transects around planned fixed ocean observatories and potentially a broader range of event, feature, or creature-focused studies.

\subsection{Expanding data stewardship}

Achievement of the full scientific potential of existing and newly developed underway technology requires expanded data stewardship at national and international levels. Efforts must consider the needs of the operational and research communities and take advantage of new technology to ensure the interoperability of marine data [21].

The need for routine underway observations, especially those from RVs, has led several countries to develop new data stewardship programs. In Germany, a new management strategy will have the vessel crew switch on a standard set of instrumentation to collect data whenever their large RVs (e.g. Meteor, Polarstern) are operating in international waters. Instrumentation is planned to include meteorology, TSG, ADCP, and bathymetry. SST and SSS are routinely collected now, but the SSS requires additional routine QC. The Polarstern is the role model for SSS in Germany, with a person dedicated to collecting daily water samples. These samples are used on land for post cruise QC, making the TSG data of high value for calibrating the Argo float salinity and for future satellite validations (e.g. SMOS and Aquarius). In the United States, the Rolling Deck to Repository (http://www.rvdata.us/overview) project envisions RV operators providing a full suite of underway observations to a central data repository. The data will be provided at the observed instrument resolution at the end of each cruise, with a subset being transferred in near-real time. These new initiatives will take advantage of advances in broadband communication with vessels at sea and improved instrument automation.

An effort has been initiated to submit quality controlled TSG data into the GTS. Critical to this effort is continued improvement of real-time and delayed-mode quality control procedures. These should include visual quality evaluation and comparisons with data obtained from other platforms, water samples, and numerical model outputs. A unified effort should be made to distribute underway data in real- and delayed-time.

Advancement in national data stewardship is a step in the right direction, but it remains difficult to obtain a 
comprehensive set of historical and current underway observations from RVs. The lack of a coordinated international approach to RV data stewardship, with consistent data and metadata, means RV observations are underutilized [20]. An international focus would facilitate the adoption of RVs making meteorological observations in real time into the VOS Scheme [57]. Furthermore, these new data stewardship initiatives, along with expansion of existing programs, can facilitate synthesis of underway ship observations with those collected by satellites, gliders, Argo, ASVs, and coastal radars.

\section{CHALLENGES FOR THE NEXT DECADE}

The largest impediment to a unified international program of underway data collection and stewardship continues to be the coordination of underway observing programs run by individual investigators and nations. Existing shipboard programs (VOS, SOOP, GOSUD, SAMOS, and IMOS), developing national ship programs, and programs focusing on other observing platforms (OceanSITES (Ocean Sustained Interdisciplinary Time series Environment observation System), Argo, etc.) should be leveraged to expand international cooperation.

\section{- Recommend:}

1. Building improved linkages between the physics, carbon, biogeochemical, and biological communities undertaking automated underway sampling in both the ocean and marine atmosphere.

2. Working towards standardized data formats, quality control methods, and metadata across national programs to make data ready for global science applications and data synthesis.

3. Pursuing methods for systematic intercomparison and calibration of sensors and measurements.

One benefit of automated multi-sensor underway observations is the facilitation of the development of satellite and model-based environmental products. Many of the required parameters are common between the underway, mooring, satellite and modeling communities and forging linkages will increase the amount of data available to all the groups.

\section{- Recommend:}

4. Developing consolidated observation sets for all underway data as a high quality validation dataset for applications in satellite calibration and validation, model validation, parameterization development and as a resource for interdisciplinary research.

Opportunities exist to ensure that most global RVs are equipped with a standard suite of underway instrumentation (e.g. meteorology, radiation, TSG,
ADCP, and bathymetry). Many vessels already carry these instruments; what is needed is an enhanced international framework to coordinate the collection and distribution of the data. The need for coordination includes distributing future cruise plans for RVs and tracking observations collected by RVs. Prior knowledge of cruises will aid the deployment of dedicated underway observing systems (e.g. direct flux systems) in high priority regions.

RVs should routinely make high quality measurements of mean meteorology, radiative fluxes and precipitation [57] and subsurface data [19]. A subset should also measure direct fluxes, directional wave spectra and other sea state information including currents with a focus on regions of high variability and gaps in the OceanSITES network, such as high latitudes. Measurements should be expanded to selected commercial and other non-RVs including those making subsurface and atmospheric profiles.

\section{- Recommend:}

Develop an international framework to coordinate the collection of underway data from RVs, promoting the value of measuring high quality underway data, providing advice on best measurement practice and facilitating data quality control, archival and distribution.

5. Provide adequate resources to maintain databases of historical and future RV cruises, and leverage ongoing national and international efforts (e.g. JCOMM-OPS (Observing Platform Support), POGO (Partnership for Observation of the Global Oceans); http://www.pogo-oceancruises.org/).

6. Identify and target new vessels providing the potential for automated underway data collection in regions otherwise under-sampled with the present observing systems. Approach agencies responsible for coordination of vessel operations for activities outside science (e.g. the International Association of Antarctic Tour Operators).

Obtaining high-quality observations using automated sensors on ships will continue to provide technical challenges in the coming decade.

\section{- Recommend:}

7. Develop and deploy automated systems for measurement of sea state, cloud cover, and cloud type.

8. Renew efforts to improve existing and develop new shipboard rain sensors.

9. Include airflow modeling into new vessel (primarily research, but merchant as possible) design to ensure that underway atmospheric systems are located so as to minimize vessel 
influence on measurements.

The envisioned underway observing system should both achieve the global view of the atmosphere and ocean needed for NWP applications while providing the higher quality, high-temporal resolution data needed to both validate this "big picture" and provide the necessary data for a wide range of ocean, atmosphere, and climate research. Due to typically dwindling national resources for ocean observing a dialog is needed to assist nations in targeting their resources toward high return projects. Any decision must balance the needs of a diverse user community and should address the rapid changes in observing system technology.

\section{- Recommend:}

10. Developing a list of high priority operational and research questions that can be addressed using underway observations.

The advantages to RVs making high quality observations in real-time, as part of the VOS Scheme, are clear. Recent extension of VOS observational metadata should ensure that such observations could be distinguished in the data stream if desired.

\section{- Recommend:}

11. Coordinate, via JCOMM and NMS, efforts to include underway-meteorological observations from operator-owned automated systems into the VOS Scheme.

Diplomatic obstacles are still an issue when vessels enter the exclusive economic zones of different countries. Acoustic sensors seem to be most problematic. There is a need for international agreement to remove such obstacles.

\section{- Recommend:}

12. All nations should participate in discussions with a newly formed IOC working group to reduce diplomatic obstacles to ocean observing.

As the ocean observing community continues to develop and provide high quality observations, every effort should be made to make these observations readily available, including to developing nations.

\section{- Recommend:}

13. All observing programs should work to engage developing countries and take advantage of whatever merchant and RV resources these countries can provide.

Ships are ideally suited to make concurrent automated underway measurements meeting many operational and research applications. Many RVs are already equipped with high-quality sensors and only a small investment is needed to ensure the observations are widely available to the user community. Further investment in new or upgraded technologies will expand the capability of the future ocean observing system.

\section{REFERENCES}

1. The Australian Integrated Marine Observing System, 2008: J. Ocean Technology 3(3), 80-81.

2. Béranger, K., B. Barnier, S. Gulev, and M. Crepon, 2006: Comparing 20 years of precipitation estimates from different sources over the world ocean. Ocean Dyn. 56, $104-138$

3. Berry, D. I., E. C. Kent, and P. K. Taylor, 2004: An analytical model of heating errors in marine air temperatures from ships. J. Atmos. Ocean Technol., 21, 1198-1215.

4. Bourassa, M. A., M. H. Freilich, D. M. Legler, W. T. Liu, and J. J. O'Brien, 1997: Wind observations from new satellite and research vessels agree. EOS, 78, 597602.

5. Bourassa, M. A., D. M. Legler, J. J. O'Brien, and S. R. Smith, 2003: SeaWinds validation with research vessels. J. Geophys. Res., 108, doi:10.1029/2001JC001081.

6. Bourassa, M. \& Co-Authors (2010). "Remotely Sensed Winds and Wind Stresses for Marine Forecasting and Ocean Modeling" in these proceedings (Vol. 2), doi:10.5270/OceanObs09.cwp.08.

7. Bradley, F., and C. Fairall, 2007: A Guide to Making Climate Quality Meteorological and Flux Measurements at Sea. NOAA Technical Memorandum OAR PSD-311, NOAA/ESRL/PSD, Boulder, CO, $108 \mathrm{pp}$.

8. Camps, A., J. Font, J. Etcheto, V. Caselles, A. Weill, I. Corbella, M. Vall-Ilossera, N. Duffo, F. Torres, R. Villarino, L. Enrique, A. Julia, C. Gabarro, J. Boutin, I. Rubio, S. C. Reising, and P. Wursteisen, 2002: Sea surface emissivity observations at L-band: first results of the Wind and Salinity Experiment WISE 2000. Geoscience and Remote Sensing, IEEE, 10, 2117-2130.

9. Curcio, J. A., P. M. McGillivary, K. Fall, A. Maffei, K. Schwehr, B. Twiggs, C. Kitts, and P. Ballou, 2006 : Self-positioning smart buoys, the "un-buoy" solution: Logistics considerations using autonomous surface craft technology and improved communications infrastructure. Procs. Mar. Technol. Soc., Boston, MS, IEEE, 1-5.

10. Dong, S., J. Sprintall, and S. T. Gille, 2006: Location of the Antarctic Polar Front from AMSR-E satellite sea surface temperature measurements. J. Phys. Oceanogr., 36, 2075-2089.

11. Dong, S., S. T. Gille, and J. Sprintall, 2007: An assessment of the Southern Ocean mixed-layer heat budget. J. Climate, 20, 4425-4442. 
12. Donlon, C., I. S. Robinson, M. Reynolds, W. Wimmer, G. Fisher, R. Edwards, and T. J. Nightingale, 2008: An infrared sea surface temperature autonomous radiometer (ISAR) for deployment aboard Volunteer Observing Ships (VOS). J. Atmos. Oceanic Tech., 25, 93-113.

13. Donlon, C. \& Co-Authors (2010). "Successes and Challenges for the Modern Sea Surface Temperature Observing System" in these proceedings (Vol. 2), doi:10.5270/OceanObs09.cwp.24.

14. Fairall, C. W., E. F. Bradley, J. E. Hare, A. A. Grachev, and J. B. Edson, 2003: Bulk parameterization of airsea fluxes: Updates and verification for the COARE algorithm. J. Clim., 16, 571-591.

15. Fairall, C. W., A. B. White, J. B. Edson, and J. E. Hare, 1997: Integrated shipboard measurement of the marine boundary layer. J. Atmos. Ocean Technol., 14, 338-359.

16. Fairall, C. \& Co-Authors (2010). "Observations to Quantify Air-Sea Fluxes and their Role in Climate Variability and Predictability" in these proceedings (Vol. 2), doi:10.5270/OceanObs09.cwp.27.

17. Flagg, C. N., G. Schwartze, E. Gottlieb, and T. Rossby, 1998: Operating an Acoustic Doppler Current Profiler aboard a container vessel. J. Atmos. Oceanic Tech., 15, 257-271.

18. GCOS, 2003: The Second Report on the Adequacy of the Global Observing Systems for Climate in Support of the UNFCCC. GCOS-82 (WMO/TD-No. 1143).

19. Goni, G. \& Co-Authors (2010). "The Ship of Opportunity Program" in these proceedings (Vol. 2), doi:10.5270/OceanObs09.cwp.35.

20. Gould, W. J. and S. R. Smith, 2006: Research vessels: Underutilized assets for climate observations. EOS, Trans Amer. Geophys. Union, 87, 214-215.

21. Hankin, S. \& Co-Authors (2010). "NetCDF-CFOPeNDAP: Standards for Ocean Data Interoperability and Object Lessons for Community Data Standards Processes" in these proceedings (Vol. 2), doi:10.5270/OceanObs09.cwp.41.

22. Holliday, N. P., M. J. Yelland, R. W. Pascal, V. R. Swail, P. K. Taylor, C. R. Griffiths, and E. C. Kent, 2006: Were extreme waves in the Rockall Trough the largest ever recorded? Geophysical Research Letters, 33, L05613, doi:10.1029/2005GL025238.

23. Hood, M. \& Co-Authors (2010). "Ship-Based Repeat Hydrography: A Strategy for a Sustained Global Program." in these proceedings (Vol. 2), doi:10.5270/OceanObs09.cwp.44.

24. Houze, R.A., Jr., 1993: Cloud Dynamics. Academic Press, 573 pp.

25. Jackson, D. L., G. A. Wick, and J. J. Bates, 2006: Nearsurface retrieval of air temperature and specific humidity using multisensor microwave satellite observations. J. Geophys. Res., 111, D10306, doi:10.1029/2005JD006431.
26. Jackson, D. L., G. A. Wick, and F. R. Robertson, 2009 Improved multi-sensor approach to satellite-retrieved near-surface specific humidity observations. $J$. Geophys. Res., 114, D16303, doi:10.1029/2008JD011341.

27. Johnson, R. H., and P. E. Ciesielski, 2000: Rainfall and radiative heating rates from TOGA COARE atmospheric budgets. J. Atmos. Sci., 57, 1497-1514.

28. Joss, J., and R. Lee, 1995: The application of radar-gauge comparisons to operational precipitation profile corrections, J. Appl. Meteorol., 34, 2612-2630

29. Kent, E. \& Co-Authors (2010). "The Voluntary Observing Ship (VOS) Scheme" in these proceedings (Vol. 2), doi:10.5270/OceanObs09.cwp.48.

30. Konda, M., N. Imasato, and A. Shibata, 1996: A new method to determine near-sea surface air temperature by using satellite data. J. Geophys. Res., 101, 14,34914,360 .

31. Lagerloef, G. \& Co-Authors (2010). "Resolving the Global Surface Salinity Field and Variations by Blending Satellite and In Situ Observations" in these proceedings (Vol. 2), doi:10.5270/OceanObs09.cwp.51.

32. Law, D. C., S. A. McLaughlin, M. J. Post, B. J. Weber, D. C. Welsh, and D. E. Wolfe, 2002: An electronically stabilized phased array system for shipborne atmospheric wind profiling, JAOT, 19 , 924-933.

33. Lee, G., and I. Zawadski, 2006: Radar calibration by gage, disdrometer, and polarimetry: Theoretical limit caused by the variability of drop size distribution and application to fast operational radar data. Journal of Hydrology, 328, 83-97.

34. Maes, C., K. Ando, T. Delcroix, W. S. Kessler, M. J. McPhaden, and D. Roemmich, 2006: Observed correlation of surface salinity, temperature and barrier layer at the eastern edge of the western Pacific warm pool. Geophys. Res. Lett., 33, L06601, doi:10.1029/2005GL024772.

35. Moat, B. I., M. J. Yelland, R. W. Pascal, and A. F. Molland, 2005: An overview of the airflow distortion at anemometer sites on ships, Int. J. Climatol., 25, 997-1006.

36. Moat, B. I., M. J. Yelland, and A. F. Molland, 2006a: Quantifying the airflow distortion over merchant ships. Part II: Application of the model results, $J$. Atmos. Ocean. Tech., 23, 351-360.

37. Moat, B. I., M. J. Yelland, R. W. Pascal, and A. F. Molland, 2006b: Quantifying the airflow distortion over merchant ships. Part I: Validation of a CFD model, J. Atmos. Ocean. Tech., 23, 341-350.

38. Moat, B. I. and M. J. Yelland, 2008: Going with the flow: state of the art marine meteorological measurements on the new NERC research vessel, Weather, 63, (6), 158-159. doi:10.1002/wea. 184 . 
39. Monteiro, P. \& Co-Authors (2010). "A Global Sea Surface Carbon Observing System: Assessment of Changing Sea Surface CO2 and Air-Sea CO2 Fluxes" in these proceedings (Vol. 2), doi:10.5270/OceanObs09.cwp.64.

40. Nieto, J. C., K. Reichert, and J. Dittmer, 1998: Use of the nautical radar as a wave monitoring instrument. Coastal Engineering, 37, 221-342.

41. Ohmura, A., J. DeLuisi, E. Dutton, A. Heimo, B. Forgan, R. T. Pinker, C. Frohlich, R. Philipona, G. KonigLanglo, C. Whitlock, B. McArthur, and K. Dehne, 1998. Baseline Surface Radiation Network (BSRN/WCRP), a new precision radiometry for climate research. Bull. Amer. Met. Soc., 79, 21152137.

42. Pedreros, R., G. Dardier, H. Dupuis, H. C. Graber, W. M. Drennan, A. Weill, C. Guerin, and P. Nacass, 2003: Momentum and heat fluxes via the eddy correlation method on the R/V L'Atalante and an ASIS buoy. $J$. Geophys. Res., 108, 3339, doi:10.1029/2002JC001449.

43. Persson, P. O. G., J. E. Hare, C. W. Fairall, and W. D. Otto, 2005: Air-sea interaction processes in warm and cold sectors of extratropical cyclonic storms observed during FASTEX. Quart. J. Roy. Meteorol. Soc., A $131,877-912$.

44. Petersen, W. A., and M. R. Schwaller, 2008: GPM Ground Validation: Science Implementation Plan Draft, NASA.

45. Petit de la Villéon, L. \& Co-Authors (2010). "Providing an Ocean In Situ Data Service for the Needs of Operational Oceanography" in these proceedings (Annex), doi:10.5270/OceanObs09.

46. Podnar, G. W., J. M. Dolan, A. Elfes, S. Stancliff, E. Lin, J. C. Hosler, T. J. Ames, J. Moisan, T. A. Moisan, J. Higinbotham, and E. A. Kulczycki, 2008: Operation of robotic science boats using the telesupervised adaptive ocean sensor fleet system. 2008 IEEE International Conference on Robotics and Automation, Pasadena, CA, IEEE, 1061-1068.

47. Popinet, S., M. Smith, and C. Stevens, 2004: Experimental and numerical study of the turbulence characteristics of airflow around a research vessel, $J$. Atmos. Ocean. Tech., 21, 1575-1589.

48. Pouliquen, S., Schmid, C., Wong, A., Guinehut, S. and Belbeoch, M., (2010). "Argo Data Management" in these proceedings (Vol. 2), doi:10.5270/OceanObs09.cwp.70.

49. Renfrew, I. A., G. W. K. Moore, P. S. Guest, and K. Bumke, 2002: A comparison of surface layer and surface turbulent-flux observations over the Labrador Sea with ECMWF analyses and NCEP reanalyses. $J$. Phys. Oceanogr., 32, 383-400.

50. Richardson, A. J., A. W. Walne, A. W. G. John, T. D. Jonas, J. A. Lindley, D. W. Sims, D. Stevens, and M. Witt: 2006. Using continuous plankton recorder data. Prog. Oceanog., 68, 27-74.
51. Rossby, T., Kim, K. \& Ortner, P. (2010). "SCOR/IAPSO 'OceanScope' Working Group" in these proceedings (Annex), doi:10.5270/OceanObs09.

52. Ryzhkov, A. V., S. E. Giangrande, V. M. Melnikov, and T. J. Schuur, 2005: Calibration Issues of DualPolarization Radar Measurements. JAOT, 22, 1138 1155.

53. Schluessel, P., L. Schanz, and G. Englisch, 1995: Retrieval of latent heat flux and longwave irradiance at the sea surface from SSM/I and AVHRR measurements. Adv. Space Research, 16, 1010710116.

54. Schulz, J., J. Meywerk, S. Ewald, and P. Schlüssel, 1997: Evaluation of Satellite-Derived Latent Heat Fluxes. $J$. Climate, 10, 2782-2795.

55. Schulz, J., P. Schluessel and H. Grassl, 1993: Water vapour in the atmospheric boundary layer over oceans from SSM/I measurements. Int. J. Remote Sens., 14, 2773-2789.

56. Smith, S. R., D. M. Legler, and K. V. Verzone, 2001: Quantifying uncertainties in NCEP reanalyses using high quality research vessel observations. J. Climate 14, 4062-4072.

57. Smith, S. \& Co-Authors (2010). "The Data Management System for the Shipboard Automated Meteorological and Oceanographic System (SAMOS) Initiative" in these proceedings (Vol. 2), doi:10.5270/OceanObs09.cwp.83.

58. Swail, V. \& Co-Authors (2010). "Wave Measurements, Needs and Developments for the Next Decade" in these proceedings (Vol. 2), doi:10.5270/OceanObs09.cwp.87.

59. Trenberth, K.E., J.T. Fasullo, and J. Kiehl, 2009: Earth's global energy budget. BAMS, 90, 311-323.

60. Trenberth, K.E., L. Smith, T. Qian, A. Dai, and J. Fasullo, 2007: Estimates of the global water budget and its annual cycle using observational and model data. J. Hydrometeor., 8, 758-769.

61. Tucker, M. J., 1956: A ship-borne wave recorder. Trans. Inst. Naval Archit., 98, 236-250. London, UK.

62. Vandemark, D., B. Chapron, J. Sun, G. H. Crescenti, and H. C. Graber, 2004: Ocean slope observations using radar backscatter and laser altimeters. Journal of Physical Oceanography, 34, 2825-2842.

63. Weller, R. A., E. F. Bradley, J. B. Edson, C. W. Fairall, I. Brooks, M. J. Yelland and R. W. Pascal, 2008: Sensors for physical fluxes at the sea surface: energy, heat, water, salt. Ocean Science, 4, 247-263,

64. Weller, R. A., E. F. Bradley and R. Lukas, 2004: The interface or air-sea flux component of the TOGA Coupled Ocean-Atmosphere Response Experiment and its impact on subsequent air-sea interaction studies. J. Oceanic Atmos. Tech., 21, 223-257. 
65. Wijesekera, H.W., D.L. Rudnick, C.A. Paulson, S.D. Pierce, W.S. Pegau, J. Mickett, and M.C. Gregg, 2005: Upper ocean heat and freshwater budgets in the eastern Pacific warm pool. J. Geophys. Res., 110, doi:10.1029/2004JC002511.

66. Wolfe, D., S. Hiller, T. Bolmer, D. Chayes, D. Forcucci, and C. Fairall, 2008: Shipboard meteorological measurements: Interpretation and quality assessments. 2nd Joint GOSUD/SAMOS Workshop, Seattle, WA, USA. Available from: http://www.coaps.fsu.edu/RVSMDC/marine_worksh op4/docs/posters/Wolfe_poster.pdf.

67. Wood, S. L, 2009: Application of an autonomous selfmooring vehicle. Sea Technology, 50, 38-40.

68. World Meteorological Organization, 1956: International Cloud Atlas. World Meteorological Organization, 62 pp. +72 plates.

69. Yasuda, A., S. Kuwashima, and Y. Kanai, 1985: A shipborne-type wave height meter for ocean going vessels, using microwave Doppler radar. IEEE Journal of Oceanic Engineering, 10, 138-143.

70. Yelland, M. J., B. I. Moat, P. K. Taylor, R. W. Pascal, J. Hutchings and V. C. Cornell, 1998: Wind stress measurements from the open ocean corrected for air flow distortion by the ship. Journal of Physical Oceanography, 28 (7), 1511 - 1526

71. Yelland, M. J., B. I. Moat, R. W. Pascal, and D. I. Berry, 2002: CFD model estimates of the airflow distortion over research ships and the impact on momentum flux measurements, J. Atmos. Ocean. Tech., 19, 1477-1499.

72. Yelland M. J., K. Bjorheim, C. Gommenginger, R. W. Pascal and B. I. Moat, 2007: In-situ wave measurements at Station Mike. 10th International workshop on wave hindcasting and forecasting \& coastal hazard assessment, Hawaii, JCOMM. 